\title{
NARRATIVA, DRAMA E ESTÍMULO COMPOSTO
}

\author{
John Somers ${ }^{2}$
}

Tradução de Beatriz A.V.Cabral

Resumo

Neste artigo o autor discute a criação de narrativas, na contemporaneidade e no contexto do ensino, a histórias pessoais, a meta-narrativas, à intertextualidade, à propriedade e autoria, aos jovens, ao Drama. Como estratégia

para entrar no mundo da ficção, apresenta a teoria do estímulo composto e suas formas de uso. Experiências em escolas são descritas e problematizadas a fim de analisar a contribuição desta teoria para o drama, o teatro e a educação.

Palavras-chave: drama, narrativas, estímulo composto.

\section{Abstract}

Here the author discusses the creation of narratives in contemporaneity and from the perspective of school, personal histories, meta-narratives, inter-textuality, to the ideas of propriety, authorship, young people and Drama. He presents the 'theory of compound stimulus' as a strategy to get into the fictional world, and their forms of use. Schools' experiences are described and problematized to carry out an analysis of the contribution of this theory to drama, theatre and education.

Keywords: drama, narratives, compound stimulus. 


\section{Introdução}

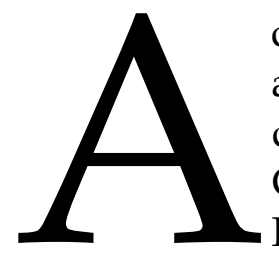

criação de narrativas é um aspecto indtispensável da experiência humana. Como comenta Barbara Hardy, 'é um ato fundamental da mente, transferido da vida para a arte' (HARDY, 1975). Quando pensamos em 'histórias' tendemos a pensar em histórias infantis, litvros de histórias e contos tradicionais. $\mathrm{Na}$ realidade, histórias permeiam nossa existência, pois sem suas perspectivas de enquadramento nós seríamos incapazes de existir além do momento da experiência. Contar e ouvir histórias nos permite três processos fundamentais:

- Organizar momentaneamente a experiência em uma série de memórias;

- Prever um futuro;

- Vivenciar através da história de outros, o que nunca experimentamos.

O primeiro indica noções de quem somos - identidade enraizada na memória. O segundo nos permite ter esperança, expectativas e organizar nossas ações. $\mathrm{O}$ terceiro forma a base de grande parte de nossa aprendizagem e educação formal.

\section{História Pessoal}

David Novitz afirma que nós construímos nossa história pessoal da mesma forma que um artista cria um trabalho de arte, selecionando e ordenando

1 Narrative, Drama and Compound Stimulus, in Education d Theatre Journal, issue 9, Atenas/GR., 2008.

2 Membro honorário do Departamento de Drama da Universidade de Exeter/UK. Aposentou-se em 2005 e desde então vem atuando como escritor, professor e orientador em países do Leste Europeu e Ásia. Obteve prêmios com programas de teatro interativos, tais como On the Edge, sobre emergências psicóticas com adolescentes, e pela Aliança Americana de Teatro por sua atuação no ensino de $3^{\circ} \mathrm{grau}$. Atuais projetos envolvem site-specific theatre e cinema. Foi editor-fundador da Revista Research in Drama Education (Routledge). experiências em um banco de memórias que se torna o significante de nossa identidade. ${ }^{3}$ Muito do que nos acontece é considerado por nossa memória como insignificante, e abandonado na sala de edição enquanto editamos o 'filme' de quem somos. Uma boa saúde mental requer que seja desenvolvida e mantida uma história pessoal coerente, que seja respeitada, tenha valor e significado. Grande parte do trabalho terapêutico é voltado a reorganizar de alguma maneira a história pessoal do paciente.

\section{Meta-histórias}

As histórias nos cercam; algumas escolhemos experimentar, tais como um romance, um filme, um programa de TV, embora quase nunca tenhamos controle sobre sua produção. Outras são invisíveis - histórias de identidade nacional, da identidade silenciada de nossa família, dos padrões de comportamento que absorvemos. Algumas são consensuais; outras são construídas com um objetivo particular em mente - demonizar outra nação, apoiar um ponto de vista político, vender algo. Uma vez que não experimentamos muito do que sabemos, mas o absorvemos de outras histórias, suas perspectivas ética/políticas e os motivos de quem as geraram são questões fundamentais que merecem nossa atenção.

Somos inevitavelmente afetados pelas histórias que encontramos. Aquelas que reforçam nossa história pessoal possuem um estado de intertextualidade, uma interação ativa de duas ou mais histórias. Desta condição surge a modificação possível da história pessoal - a ambição de todo publicitário.

\section{A propriedade das histórias}

Histórias eram usadas para preservar a tribo e, em algumas partes do mundo ainda são. Tais comunidades possuem e

3 NOVITZ, D. Memory, Identity, Community. New York: Suny Press, 1997. 
contam histórias que tenham relevância para elas - sobre seus ancestrais, suas crenças, para explicar as forças naturais. Todas as culturas formalizam seu sistema de crenças na forma de religiões, envolvendo o transcendental, espiritual e inefável, geralmente mantidos por contadores de histórias da comunidade. Os contadores de histórias passam por um longo aprendizado, pois muitas histórias são orais e podem somente ser aprendidas, se ouvidas.

$\mathrm{Na}$ medida em que a comunicação espalhou-se pelo mundo, algumas histórias tornaram-se dominantes. A disseminação do cristianismo foi um exemplo precoce e contínuo. Estamos hoje cercados por histórias; a maioria inspirada comercialmente. Ao redor do mundo, pessoas subscrevem a história corporativa da Nike, vêm filmes da Disney, ou expressam pesar pela morte de uma celebridade com quem nunca se encontraram. Nas remotas florestas da Nova Guiné as vilas usam geradores de TV que recebem a programação de Rupert Murdoch. ${ }^{4}$

\section{Jovens e Histórias}

Contar histórias éum dos maiores meios pelos quais os adultos representam o mundo para as crianças, repassando as histórias seminais que encorajam conhecimento, entendimento, ações apropriadas e os princípios do comportamento moral. O avanço tecnológico introduz uma grande variedade de histórias e tal diversidade permite que as crianças se adaptem às suas estruturas - tais como o RPG online. A internet oferece um mundo virtual no qual jogadores de remotas partes do mundo adquirem um forte sentido de comunidade que se espalha por todos os continentes. Tais condições criam o contexto de diversidade e escolha. O que é preocupante, entretanto, é a crescente hegemonia de certas histórias. Onde os interesses comerciais controlam a realização e a difusão de histórias, os

4 Conversa com testemunhas. Idea world Congress, Brisbane, 1995. consumidores são encorajados a uma dieta não saudável de produtos que os encorajam a adotar valores e comportamento globais alheios à sua cultura.

Embora a intertextualidade da história pessoal e da narrativa comercial possa ser estimulante, é também importante que crianças e adultos produzam suas próprias histórias. Com liberdade de escolha, os indivíduos optam por histórias que tenham maior relevância para eles - que permitam uma interação produtiva com 'quem eles são'. É por esta razão que duas pessoas podem discordar sobre os níveis de interesse que eles têm em um livro, filme ou peça. Quando a história funciona, os elementos da narrativa interconectamse produtivamente com os pensamentos, as memórias e as questões que 'importam' para eles no momento que a estão vivenciando. ${ }^{5}$

\section{Drama e História}

Participantes em Drama na Educação são encorajados a entrar em um mundo ficcional. Este mundo tem similaridades àqueles apreciados pelas crianças em seu jogo. A diferença é que o objeto do jogo é escolhido, conscientemente, pelo líder ou participantes, e o meio pelo qual o objeto é formatado, a linguagem dramática, é deliberadamente adquirido através da aprendizagem de habilidades. Não há dúvida que os líderes do drama almejam sua eficácia, e também a mudança de atitudes, embora eles sejam geralmente relutantes em admiti-lo e não vejam formas confiáveis de julgar se esta mudança de atitude ocorreu. ${ }^{6}$ Minha pesquisa mostra a possibilidade de mudança de atitudes (SOMERS, 1996). Embora professores sejam cautelosos em proclamar mudanças positivas de atitude,

5 Veja SOMERS, J. Jukebox of the Mind, não publicado, disponível pelo autor.

6 Veja SOMERS, J. How Teachers Choose What to Teach. In: MILLER; SAXTON. International Conversations, IDIERI and UVIC, Canada. 
o objetivo implícito dos professores é desenvolver pessoas mais humanas e sensíveis, e eles terão problemas se for sugerido que seus alunos permanecem intocáveis pela experiência do drama, ou mesmo se que tornaram mais negativos em decorrência dela (SOMERS, 1999).

Umaexperiênciadedramabemsucedida é implicitamente terapêutica, embora não diretamente como Dramaterapia ou Psicodrama. Um participante em $\mathrm{DIE}^{7}$ compreende a experiência dramática através da referência à sua memória e história pessoal; mais importante e crucial é que a experiência do drama também possibilita reeditar sua história pessoal, e conectar-se consigo próprio.

Argumentei acima que importa qual $e ́$ a história introduzida no drama. Uma experiência bem sucedida não pode acontecer se os participantes não acham relevância no material explorado. Todo drama contém uma tensão que energiza o processo de investigação através da improvisação. O trabalho do líder é assegurar que os participantes estejam produtivamente engajados na exploração de tal tensão. $O$ problema introduzido é raramente direto; se o fosse perderia a multidimensionalidade requerida para sua eficácia. Isto requer conhecimento tanto das características culturais quanto dos interesses da faixa etária. Bons líderes operam com (geralmente de forma não articulada) conhecimentos da psicologia do desenvolvimento.

\section{Trabalhando em dois níveis}

Parte do impacto está baseado no trabalho em dois níveis interconectados e que afetam um ao outro - o nível social real dos participantes, e o nível simbólico da linguagem do drama. É difícil o engajamento efetivo com o nível simbólico se a saúde social do grupo é

7 DIE é a sigla para ‘drama in education'; será mantida daqui para frente. fraca. O líder deve criar boas condições sociais para os participantes entrarem no trabalho com confiança em si e nos outros. Este é um objetivo fundamental do início do trabalho, que permite compartilhar e respeitar diferenças.

\section{Estratégias para entrar no mundo da ficção}

Há uma enorme variedade de recursos para introduzir os participantes no mundo da ficção. Geralmente o estímulo torna-se menos importante à medida que o grupo se fortalece. O estímulo composto, aqui descrito, pode ser visto como um foguete que conduz a nave principal - a história, seus personagens e o mundo em que vivem - em vôo, antes de se soltar. A energia e o interesse gerados pelo estímulo composto promovem o 'reforço' inicial para a criação da história, e uma vez esta tenha sido iniciada, serve como uma referência contínua no processo de criação.

\section{A teoria do estímulo composto}

$\begin{array}{clll}\text { Todos } & \text { os } & \text { objetos } & \text { inanimados } \\ \text { designados } & \text { para uso pessoal são }\end{array}$ impregnados pelos seus donos. Uma ferramenta pode sugerir o trabalho e o trabalhador; um item de vestuário o seu usuário e seu comportamento; uma carta o motivo de sua escrita e um relacionamento. As pessoas que enterravam seus mortos com objetos significantes de suas vidas (e seus cavalos, parentes e servidores, por exemplo) esperavam que os objetos enterrados fossem permitir aos mortos conduzir uma nova história no mundo além daquele que deixaram. O poder da história associada com os objetos era suficiente para convencer os vivos que o morto iria proceder com uma existência.

Um artefato individual tem um potencial limitado para gerar histórias. A imagem de um bebê, por exemplo, torna difícil criar uma história que vá além do conceito do 'bebê'. Se adicionado o som 
de um metrônomo à imagem, um novo ímpeto para a criação da história é gerado. A história geralmente não ficará centrada na imagem do 'bebê' ou no 'tique-taque' do metrônomo, mas será mantida no campo de força de sua interação.

Os documentos sugeridos podem ser mais sutis ou mais complexos - a formalidade da carta de um advogado pode ser confrontada com uma nota pessoal. Os usuários evocam visões de um relacionamento que deu errado, uma intimidade que agora é exposta para disputa legal. Como o bebê e o metrônomo, a história é para ser encontrada no cruzamento entre os documentos.

O estímulo composto inclui diferentes artefatos - objetos, fotografias, cartas e outros documentos, incluídos em um container apropriado. A significância é dada pela justaposição cuidadosa de seu conteúdo - o relacionamento entre eles e o detalhe dos objetos sugere motivação e ação humana.

Aqui reside o segredo da criação de um estímulo composto. Os elementos da história que cada artefato representa devem, quando justapostos, criar uma rede de relacionamentos que nem sejam rapidamente compreendidos para evitar que a história torne-se imediatamente óbvia, nem tão distantes um do outro para que as possibilidades narrativas possam emergir.

Isto é possível quando se dá informação suficiente para ligações plausíveis entre os artefatos, cuja natureza só possa ser definida pela exploração dramática. Exemplos: colocar nomes dentre de cartas que ecoem em forma de iniciais em outro artefato; correspondência de datas; uma fotografia que possa sugerir uma pessoa mencionada em um documento oficial; uma lembrança que possa ser interpretada como resultado de uma relação sugerida em um diário.

\section{Formas de uso}

Quando confrontados com um estímulo composto, os usuários devem investir imaginativamente em seu uso para gerar uma história. Como em todo trabalho de drama, um espírito lúdico é requerido, uma vontade de entrar no espírito do' jogo'. Como tal, o líder deve conduzir exercícios iniciais com os participantes para que estes 'aprendam as regras do jogo'. As regras aqui são de especulação, hipótese e postulação através do jogo, para que seja reconhecida que a autenticidade, quando alcançada, foi criada para esta história e não é 'real'.

Há duas questões básicas que sempre coloco para aqueles usando o estímulo composto: 'quem são estas pessoas?' e 'o que está acontecendo com elas?' Há muito a se ganhar com isso através da discussão e especulação.

Os participantes entram então na etapa da improvisação para explorar as situações sugeridas pela história. Este é o uso do espaço do drama como laboratório.

A questão guia aqui é 'Que situações vocês querem criar que lhes permitirá descobrir mais sobre estas pessoas?' É essencial que a tensão dramática exista dentro da improvisação para que haja energia dramática, e uma das habilidades que os participantes desenvolvem nesta etapa é identificar situações que contenham tal tensão. Os participantes trabalham melhor em pequenos grupos, usando o drama como um instrumento de pesquisa. É nesta fase que as pessoas da história adquirem vida, pois o drama permite criar detalhes da experiência humana. Assim, os mesmos personagens que emergem como egoístas em um grupo podem ser descobertos como generosos em outro. As improvisações esclarecem por um lado a história básica consegue coerência, mas complicam poroutrolado-maiores dilemas e questões emergem e exigem investigação. À medida que a improvisação progride, há um aumento de cruzamento de referências entre as improvisações individuais.

A terceira etapa é para a seleção e formatação. Aqui o grupo peneira a informação que descobriu na etapa da pesquisa para selecionar oque temcoerência e valor para a história e seus personagens. A maneira de descobrir coisas na etapa 
da pesquisa pode não ser a maneira de registrá-las na etapa da formatação. Os participantes podem, por exemplo, ter descoberto algo sobre um relacionamento através de improvisação naturalista, mas decidem formatá-la de forma estilizada. O que é formatado poderia ser visto como o insight, um saber que o grupo adquiriu através da pesquisa. É ao selecionar e dar forma que o grupo entende a significância da história que criaram e habitaram.

A quarta etapa é da comunicação -, o que foi selecionado e formatado é comunicado para outros - usualmente outros membros do grande grupo. Se feito dentro do grupo, a comunicação é oferecida como o resultado de um processo de pesquisa para os demais companheiros pesquisadores. Muitos dos apetrechos da performance não estão, portanto, presentes. $\mathrm{O}$ que recebemos é a história básica, ordenada e formatada para ter coerência. Esta etapa pode usar recursos com habilidade, entretanto - o uso da narração, cantos, música instrumental ao vivo - para unir os fragmentos da história dramatizada. O essencial é que o material comunicado tenha forma e força dramática. Quase sempre, aplauso não é apropriado, pois estamos apenas compartilhando o resultado de um processo de pesquisa. Com uma história sofisticada e a vontade do grupo, entretanto, a etapa da comunicação pode ser desenvolvida para apresentar um espetáculo para um público mais formal.

\section{Exemplos de estímulo composto}

Pretendi incluir fotografias para apresentar a natureza do estímulo composto. Mas nenhuma foto compensaria o toque e a leitura dos artefatos reais; espero que o leitor descubra os segredos das decisões essenciais ao escolher os ingredientes de um estímulo. Dependendo do tamanho do grupo, a forma ideal de trabalho é a circular (se não exceder vinte participantes), ou um semi-círculo com diversas filas, se forem mais. É possível duplicar o estímulo composto para facilitar seu exame, mas isto pode prejudicar o seu senso de singularidade.

\section{Exemplo 1}

A primeira descrição é de uma caixa de memórias que tenho usado em muitos países em muitos anos. Ela nunca falha em intrigar. O container é uma caixa de cigarro com fita vermelha. Eu introduzo a caixa dizendo que fui a uma casa de leilão para comprar uma cômoda. Lá, selecionei a cômoda entre outros móveis que pareciam provenientes de uma mesma casa - sugerindo o desmonte de uma casa após a morte de seu dono. A cômoda parecia vazia, exceto por folhas de jornal no fundo de cada gaveta. Chegando em casa, entretanto, descobri a caixa de cigarros. Neste ponto eu desato a fita, abro a caixa e convido os participantes, alternadamente, a pegar um dos artefatos e descrevê-lo. Estes são então dispostos sobre uma toalha branca no centro do círculo.

A caixa contém material da época de 1920: Uma flor seca; cabeças de semente de uma planta chamada 'honestidade' (na Inglaterra); uma fotografia de um grupo posando em roupas formais; a fotografia de um homem; um cartão de aniversário com a seguinte mensagem escrita à mão:

\footnotetext{
"Desejo a você felizes retornos deste dia". Leia cuidadosamente o texto no verso deste cartão. E aceite uma pequena lembrança de amizade de minha parte. Sinceramente, sua Florence.
}

Uma carta manuscrita com o seguinte texto:

Cara Florence,

Grandes novidades! Como você sabe, eu havia lhe dito que havia escrito uma carta a meu tio Richard, de Vermont bem, ele me respondeu esta manhã, e me diz que eu me prepare para trabalhar duro, pode haver uma oportunidade 
para mim. Florence, esta pode ser a chance que eu estava esperando. Eu sei que depois do que eu passei, jamais poderia permanecer em Bleadon; mas um dia, quando eu fizer minha fortuna, eu retornarei.

Consegui uma vaga no Oriole, o cruzador que parte esta sexta, e como tenho assuntos a resolver em Londres, sigo para lá esta tarde.

Minha mãe está informando a todos que a comemoração de meu aniversário foi cancelada. Lamento que isto nos roube outra oportunidade de um encontro, mas eu sei que após nossa discussão no jardim da festa de sábado, você estará feliz por mim.

Obrigado por ajudar-me a ver as coisas tão claramente. Eu lhe escreverei da América assim que me assentar.

Com afeto, seu amigo,

Peter

Histórias de diferentes tipos emergem deste estímulo composto. A descrição de uma delas pode ajudar o leitor a entender como o estímulo funciona para facilitar a construção de histórias:

Uma mulher, Florence Astell, de Bleadon, uma pequena vila na região de Cambridge, encontrou um homem, Peter Connaught muitas vezes enquanto eram jovens. Em uma festa ao ar livre, nos jardins da Reitoria, eles se encontraram novamente, e Florence ajudou Peter a chegar a um acordo consigo mesmo, sobre seus desentendimentos com seu pai, os quais o levaram e ser excluído da firma da família. Na ocasião ele a convida para sua festa de aniversário. Ela sente atração por ele, e pensa que ele sinta o mesmo por ela, embora nada tenha sido explicitado. Ele colhe uma flor do jardim da reitoria e a coloca na frente de seu vestido, e em outro momento ele toca seu pescoço com uma pena encontrada no jardim. Na antecipação da festa de aniversário, ela escreve um cartão para ele, mas recebe a carta antes que tenha tido a chance de enviá-lo. Ela não o revê antes que ele deixe Londres. Ela mantém os objetos na caixa como memória de um relacionamento que nunca floresceu.
Os grupos usam improvisações para explorar situações da história - o que aconteceu com ambos durante o passeio pelo jardim; como Florence reagiu quando sua mãelhecontou que a festa de aniversário havia sido cancelada; o que aconteceu quando Peter retornou a Bleadon algum tempo depois e encontrou Florence, etc.

Como dito anteriormente, cada peça de informação útil obtida a partir de improvisações é usada para esclarecer e reforçar a história dos participantes.

É possível usar este estímulo composto para explorar durante horas os relacionamentos destas pessoas inseridas no contexto social de 1920. É também possível estender o trabalho para criar resultados mais sofisticados, incluindo laboratórios de atuação.

\section{Exemplo 2}

Este estímulo composto foi usado como parte de um programa de Teatro Educação (TIE) ${ }^{8}$ aplicado a estudantes de 13 anos de idade em escolas do condado de Devon, Inglaterra. O estímulo foi usado para envolver os participantes na criação de uma história anterior à visita de um grupo de Teatro Educação9 ${ }^{9}$. Como nós

8 Teatro na Educação envolve o uso de teatro em contextos educacionais. Ele sempre inclui um elemento de performance que está inserido em um programa interativo de outras atividades e levam os estudantes e explorar as motivações de personagens e serem capazes de influenciar a história através de seu engajamento, geralmente de ordem moral, com a história e seus personagens.

90 termo Teatro Educação, nos países de língua inglesa, se refere a grupos de teatro, cujos integrantes tem formação em teatro e em educação, e montam espetáculos de cunho interativo para serem apresentados em escolas. 0 grupo envolve usualmente uma turma de alunos por vez, na construção da ambientação cênica, na análise e experimentações em torno dos conceitos e situações-chave da peça, e realiza ao final, um amplo debate sobre o tema e a estética do espetáculo. 0 setor de educação das principais cidades da Inglaterra fornece às escolas, anualmente, um livreto com a listagem dos grupos e as ofertas para aquele ano, o qual inclui informações sobre o espetáculo, telefones de contato, responsável pela produção e nome de um educador que tenha assistido o mesmo e possa dar referências. A escola que estiver interessada em um espetáculo entra em contato com o setor de educação (council of education) e este financia a ida do grupo à escola. (Nota da Tradutora) 
trabalhamos durante o período de um dia com duzentos e setenta estudantes em três grupos de noventa (cada grupo contendo três turmas de trinta alunos), foi decidido duplicar o estímulo para facilitar seu uso. Assim, cada turma de trinta recebeu seis estímulos compostos, de forma que a discussão pudesse acontecer em grupos de cinco. Como cinquenta e quatro estímulos compostos foram necessários para facilitar a duplicação, nós restringimos seu conteúdo a documentos e uma fotografia.

O pacote continha:

- Um cartão de registro escolar confidencial, de Lucy White, 14 anos. Nele estão registrados uma série de declarações de professores, incluindo comentários sobre a adaptação inicial bem sucedida de Lucy à nova escola na transferência da escola primária para a secundária. ${ }^{10}$ À medida que Lucy fica mais velha, é anotado que uma menina chamada Sarah Richards cada vez mais a pressiona, e põe em risco seu relacionamento com sua melhor amiga, Rachel;

- Um postal de Rachel para Lucy enquanto a primeira estava em férias;

- Uma página de um caderno de rascunho, com um trabalho de francês, e rabiscos com letras distintas sobre o trabalho;

- Um documento dobrado e colado com 'manter-se fora' ostensivamente marcado no seu exterior. Ao ser aberto, o documento revela a fotografia de um grupo de alunos rotulada 'nossa turma de francês numa viagem a Caen' que foi marcada para mostrar os sentimentos de seu proprietário em relação a outros membros da classe;

- Um relatório da Polícia de Devon a Cornwall por um 'Detetive Constable Walters' que foi chamado ao Departamento de Acidente e Emergência do hospital local às 2:28 da madrugada para ver uma jovem, Rachel Hurst, que havia sido trazida inconsciente com um nível de álcool no sangue três vezes maior do que o limite

10 As escolas primárias e secundárias inglesas estão situadas em prédios e locais distintos. (Nota da Tradutora) permitido para adultos. Ele também dá parte do contexto no qual o acidente ocorreu, e quais linhas de investigação a polícia está contemplando;

- Um tipo de "relatório especial", para Sarah Richards, dizendo que ela é obrigada a tomar parte de cada classe que ela frequenta, assinado pelo professor após a entrada de um comentário sobre o comportamento de Sara;

- Cinco páginas do diário de Lucy revelando pensamentos íntimos sobre relacionamentos, pressões, medos e esperanças;

- Uma página de registros de chamadas de ambulância, do hospital local dando detalhes breves das circunstâncias de uma chamada por alguém solicitando uma ambulância em um dado endereço, e o registro da partida de paramédicos e uma ambulância;

- Um conjunto de quatro fotos, de cabine fotográfica, de duas garotas;

- Um recibo de compra de considerável quantidade de álcool;

- Um convite para uma "festa do pijama e vídeo".

Todos os documentos estavam contidos numa sacola plástica com propaganda de uma determinada loja que vende álcool.

Os professores das escolas foram informados por um membro do grupo de TIE sobre como usar o estímulo composto com seus alunos. Tendo organizado a classe em seis grupos de cinco, o professor contou aos alunos que um grupo viria à escola na próxima semana para trabalhar com questões de uso de álcool. Eles iriam trabalhar sobre uma história que envolvia o conteúdo de uma sacola e que, antes da chegada do grupo de TIE, seu trabalho seria descobrir tanto quanto pudessem sobre as pessoas na história e o que estava acontecendo com elas. Os professores, na sequencia, relataram um alto nível de interesse e envolvimento com os conteúdos da sacola e a história emergente (Veja COUSINS; SOMERS, 2001).

Durante a semana seguinte o time de TIE visitou as escolas, e apresentou uma performance de cerca de 20 minutos, 
mostrando uma história que associava o conteúdo da sacola. Os alunos puderam então encontrar Sarah Richards e observar seu afeto por Lucy e Rachel; eles viram as circunstâncias nas quais Lucy e Rachel tiraram a fotografia na cabine; eles testemunharam comoafesta se transformou de uma festa de pijama e vídeo inocente em uma festa onde bebida pesada foi obtida e consumida - particularmente por Rachel, que foi parcialmente traída por sua grande amiga Lucy que estava sob a influência maligna de Sarah Richards.

Após a performance, os estudantes foram solicitados a decidir quem foi responsável, de alguma maneira, por Rachel estar na Unidade de Terapia Intensiva (ela engasgou com o próprio vômito e estava inconsciente). Para auxiliar a discussão, grandes cartões mostrando os nomes e fotografias dos personagens foram entregues às três turmas presentes em cada uma das três apresentações do programa. Como foco para discussão e tomada de decisão, eles foram convidados a ordenar os cartões de acordo com a responsabilidade dos personagens por Rachel estar no hospital. Estes inclueíam os pais de Lucy, por exemplo, que saíram de casa enquanto a festa acontecia. Durante as discussões (cada turma em sala separada) eles poderiam convidar qualquer personagem para ficar na berlinda, e perguntar qualquer questão para esclarecer a história.

Finalmente, todas as três classes retornaram ao espaço da performance e seus cartões foram dispostos em três colunas - uma para cada classe - na ordem em que eles acharam que os personagens tinham responsabilidade pela estadia de Rachel no hospital. Uma discussão seguiuse sobre a razão pela qual colocaram os personagens naquela ordem. Os professores prosseguiram com a atividade na semana seguinte durante seus períodos matinais de 20 minutos para orientações.

Uma semana mais tarde, como 'fechamento' do programa e sua história, uma carta foi enviada para cada classe pela mãe de Rachel. Esta informava que
Rachel estava agora fora do tratamento intensivo e estaria logo em casa. A carta agradecia aos estudantes por sua ajuda em desvelar os eventos que a levaram ao hospital. Em acréscimo às informações dadas aos professores que usariam o estímulo composto com seus alunos, lhes foram também entregue notas delineando a natureza doprograma epossíveisatividades para prosseguir com o que pudesse emergir dele. Como a apresentação do programa de TIE usualmente faz parte do programa de educação e saúde da escola, as escolas muitas vezes usam material adicional escolhido por elas próprias. ${ }^{11}$

Exemplo 3

Este estímulo composto foi usado em uma classe de vinte alunos de habilidades mistas, em uma escola urbana no sudoeste da Inglaterra. Os estudantes haviam completado um trabalho sobre a Peste Negra (denominação apropriada Praga Bubônica), uma doença que varreu a Europa no século XIV, e que estima-se tenha matado a metade de seus habitantes. $\mathrm{O}$ objetivo do trabalho foi inserir a performancenotrabalhocurricularnormal da turma e usar o estímulo composto para iniciar a construção de uma história que levaria a uma apresentação para os demais alunos.

Foi entregue aos alunos uma caixa contendo material arqueológico e dito a eles que ela fazia parte do arquivo da Universidade de Exeter. Foi explicado que seu conteúdo fora descoberto em Devon. ${ }^{12}$ Um envelope, com o mesmo número de identificação da caixa incluía a imagem de uma vila do século XIV, feita por um artista após a escavação arqueológica. Tudo indicava que o conteúdo da caixa pudesse ter sido descoberto na base de uma

11 Para uma melhor avaliação deste programa, ver COUSINS; SOMERS. The Use of Theatre in Education in Health Education. (2001) Material não publicado, disponível pelo autor.

12 A escola está localizada em Exeter/Devon. Nota da tradutora. 
dos postes de demarcação das escavações assinalado com uma cruz sobre a imagem incluída no envelope.

A maioria dos objetos era ou de minha posse ou fora construído por mim. A moeda e os fragmentos de cerâmica pertenciam ao Museu de Exeter. Com exceção das peças maiores, de madeira, cada artefato estava contido em um container selado. Haviam 21 containers, um para cada estudante abrir. Os estudantes vieram à frente, um por vez, quebraram o selo e os abriram. Eles tiraram o conteúdo do papel que o embrulhava e o descreveram para os outros. Os artefatos foram dispostos em uma prancha inclinada, coberta por tecido, para facilitar a observação e a criação de relações entre eles. O conteúdo da caixa, todo etiquetado para 'identificação arqueológica', era:

- Uma ferradura; grãos de trigo e fragmentos da sacola de pano que os havia contido; um registro gráfico indicando os números de mortes em cada família; um cacho de ervas; fragmentos de cerâmica; um desenho de uma jovem mulher; fragmentos de duas cartas; um bracelete de prata; pedaços de uma madeira podre; uma bolsa com cordão de couro contendo moedas do século XIV; fragmentos de um texto da bíblia; um copo de chifre; fragmentos de papel; uma luva de couro parcialmente decomposta.

Após discutir cada objeto, o grupo começou a explorar os possíveis relacionamentos entre eles - a madeira podre seria parte de uma caixa na qual os demais materiais haviam sido enterrados na esquina de uma das casas da vila. A partir dos numerais romanos, eles decifraram a data do retrato da mulher como sendo em 1348, a época da Peste Negra em Exeter. Após o exame dos objetos, em pares, desenvolveram uma história que os associasse. A linguagem dos documentos foi decifrada e digitada. As do texto que estavam incompletas foram reconstruídas. Uma cópia de todos os documentos foi dada a cada um, para que no final de semana criasse uma história que correspondesse à evidência do estímulo composto, explicando porque estes objetos haviam sido coletados e enterrados.

$\mathrm{Na}$ segunda-feira os artefatos foram expostos - deveriam assumir o papel de 'detetives' para descobrir mais sobreas pessoas associadas com os artefatos. Discutimos as histórias que eles haviam criado e buscamos coerência. Após um tempo, formaram grupos de cinco para realizar improvisações e começar a esclarecer a história. As cenas foram compartilhadas e discutidas. Após várias sessões trabalhando desta forma, foi decidido um contexto e uma estrutura para as cenas. Um pequeno grupo foi responsável por cada cena, mas esta poderia incluir tantos outros quantos eles escolhessem. Um deles descobriu um conjunto de números na tampa da caixa que ele pensou que poderia ser um mapa de referência. Ao examinar o mapa da região, descobriu que os arqueólogos desenterraram os artefatos exatamente nolocal da escola. Isto impulsionou a investigação.

Música que eles já haviam composto em outra disciplina foi modificada e integrada, e com narração, técnicas de drama naturalista ou estilizadas, a peça foi criada e apresentada para duzentas pessoas - colegas e pais. Os estudantes se apresentaram com calças e camisetas pretas, e pés descalços.

Os três exemplos dados descrevem o uso do estímulo composto em três contextos contrastantes. $\mathrm{O}$ exemplo 1 pode ser usado em drama que possa desenvolver-se para apresentação. Alternativamente, ele poderia ser adaptado para focalizar uma situação histórica em particular, ou para lidar com questões de relacionamento, família ou migração. Oexemplo2mostracomo oestímulo composto pode ser usado para levantar questões sociais. Ele pode ser adaptado para lidar com questões tais como bullying ou uso de drogas, por exemplo. O exemplo 3 lida com uma situação histórica distante vivenciada através da investigação dramática provocada pelo estímulo composto. Ela poderia ser adaptada para qualquer período.

Em qualquer dos casos deve haver respeito pela história criada. $\mathrm{O}$ conhecimento que emerge da exploração 
no palco é frequentemente provocante e tentador e deve ser tratado como tal. As improvisações devem ser tratadas como uma maneira de levantar possibilidades em vez de ensaio de um determinado conhecimento. Somente se o drama levar os participantes além do entendimento adquirido pela discussão, o exercício terá verdadeiramente funcionado. O líder do grupo precisa decidir como ele deseja levar os participantes a usar o ímpeto da criação da história gerada pelo estímulo composto.

\section{Conclusão}

Eu não reivindico a ideia do 'estímulo composto' como inovação. Eu sei que muitas 'caixas de histórias' e 'pacotes de drama' foram usados no passado e descritos em publicações. O que eu tentei fazer aqui, entretanto, foi desvendar a base na qual estes estímulos funcionam, e expor a teoria subjacente de forma a auxiliar sua criação e uso. A fim de estender meu conhecimento sobre sua prática e teoria, eu estarei interessado em ouvir como suas experiências com o uso dos estímulos compostos em drama, reforçam ou desafiam o que eu disse aqui.

\section{Referências bibliográficas}

COUSINS, H. \& SOMERS, J. The Use of Theatre in Education in Health Education. 2001. (não publicado)

HARDY, B. The Narrative Imagination. In: The Cool Web, 1975.

SOMERS, J. 'The Nature of Learning in Drama in Education. In: SOMERS, J. (Ed.) Drama and Theatre in Education: contemporary research. York (Canada); Captus Press, 1996. 